\title{
La Democracia gobernante y preservación de gobernabilidad en El Salvador \\ Por: GOdOFREdo AguiLLÓN
}

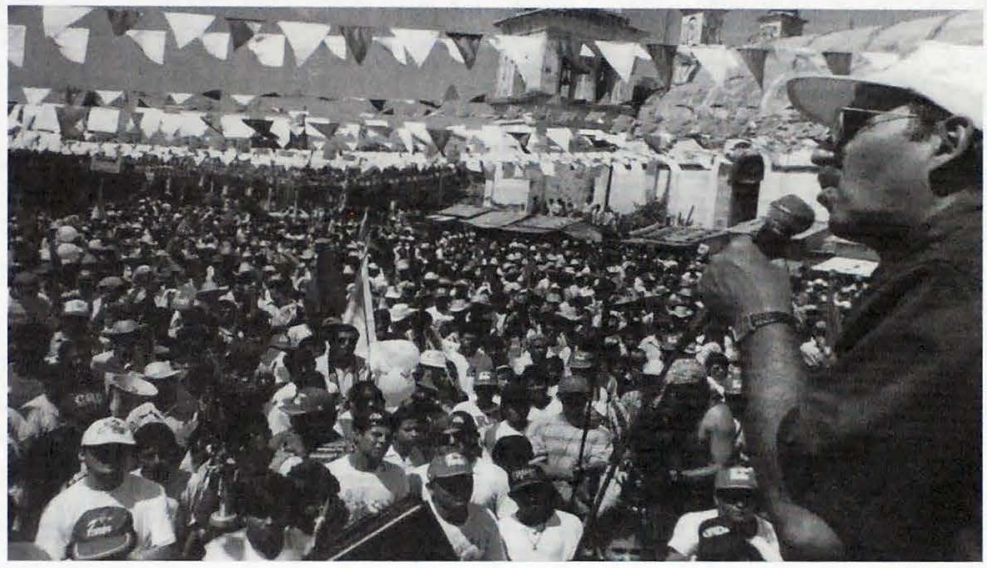

$\mathrm{E}$ sta investigación está organizada en dos partes interrelacionadas entre sí, una que sirve eminentemente de marco conceptual con fines heurísticos y de carácter epistemológicos, para situar la discusión de la temática en su contexto histórico y de desarrollo temporal; y la otra donde se analiza la situación de El Salvador a la luz de las reflexiones de la unidad precedente, principalmente, porque esa es la base para entender el proceso social, económico y político que está de trasfondo en el tema seleccionado. Cualquier profundización sobre argumentos esgrimidos en estas líneas, pueden ser consultadas en la investigación completa.

El interés que mueve a la reflexión y discusión sobre el problema elegido en este trabajo, no es otro que el de mostrar las graves limitaciones que son sintomáticas a la democracia liberal (democracia gobernable), como método empírico para elegir a las auroridades, el cual es glorificado, sin mayor discusión, por el gobierno y grupos reducidos con poder en la sociedad, en aras de proteger esencialmente sus intereses de clase garantizados por el sistema establecido.

Para algunos, sin embargo, no es el mecanismo adecuado que responde a las aspiraciones y necesidades de la inmensa mayoría de latinoamericanos, en general, y de los salvadoreños, en particular; a quienes, por cierto, de forma perceptible se les reduce a masa votante, inducidos a ejercer únicamente su derecho político de acuerdo a lo que les permite esa democracia procedimental, donde no cuentan con capacidad de influir en la toma de decisiones que afectan sus niveles de vida, luego que perdieron su soberania popular, que convoca y concita dicha democracia periódicamente.

A lo anterior se suma otra categoría que se ha convertido en comodín en los tiempos actuales, la gobernabilidad. Luego de la arremetida conservadora de mediados del decenio de los setentas del siglo XX, a la cual incluso se le adjudica un adjetivo para forzarla hacia algo distinto del autoritarismo, abreviada en dos palabras: gobernabilidad democrática. Esta evocación a dicha categoría, está presente en los pronunciamientos y discursos de las instituciones gubernamentales que representan al Estado y también en las agencias no gubernamentales, sin discutir el trasfondo ideológico que reviste en la actualidad esa categoría, tras la proclamación del fin de la ideología y de la historia con notorio tinte liberal-conservador.

Negar realidades complejas y conflictivas, contradictorias e históricas, así como hondas desigualdades sociales, económicas y sociales, están en la base de encubrimiento de toda apelación a la 
gobernabilidad; por tanto, problematizar su encantamiento y develar su intencionalidad hacia el sistema capitalista como totalidad, forma parte de nuestros ejes de discusión articulado con la concepción de democracia liberal. Desmontar las intenciones que encierran esas categorias propugnadas y difundidas por diferentes actores de poder, que no privilegian cambios ni transformaciones en la sociedad, reviste capital importancia en estos momentos cruciales de grandes definiciones que apuntalen hacia un proyecto alternativo de gran alcance nacional, centrado en las personas y sus proyectos de vida.

Toda la primera parte del trabajo es una reflexión y discusión en torno a los conceptos que se han vuelto comunes en nuestro medio, tales como transición a la democracia, gobernabilidad (con su adjetivo de gobernabilidad democrática) y, por supuesto, la práctica de la democracia liberal, con sus mecanismos y rituales temporales para elegir a los gobernantes.

Comprender este complejo problema, que no es nada fácil (prima facie), para ofrecer una visión distinta arraigada en cuestiones normativas, implica conocer y analizar la democracia que vivimos y sus alegatos de gobernabilidad, que se muestran como una necesidad de estabilidad, así como revelar sus hondas contradicciones y sus fuertes vacios de cara a las necesidades más apremiantes de amplios estratos de población, pues la paradoja consiste en delegar autoridad a través de procesos electorales, mientras no tienen autoridad para elegir sus destinos participando en las decisiones vitales de la nación.

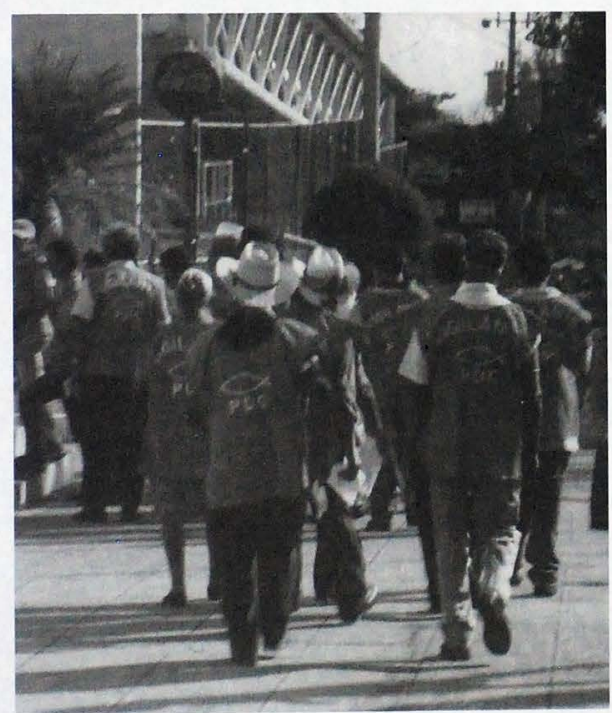

En la década de los setenta del siglo XX, por toda una constelación de hechos que concitaron esperanzas de cambio social, el concepto de legitimidad era hegemónico en el ámbito de las ciencias sociales, coincidiendo con el movimiento crítico contra la guerra de Vietnam, las movilizaciones obreras, en buena parte de Europa, el gobierno de la Unidad Popular en Chile, la revolución de los claveles en Portugal, el agotamiento del modelo capitalista, la crisis del petróleo, etc., que en general, constituían un cuestionamiento del sistema capitalista y, por tanto, exigían su transformación. Fue una época marcada por conflictos sociopolíticos que desafiaban la ansiada legitimidad del orden establecido mediante posiciones distintas e incluso radicales.

La tensión que se abrió, no era para menos, en las sociedades subdesarrolladas, a tal grado que exigían una relectura de la situación de parte de los defensores del sistema capitalista frente a las posiciones radicales que proclamaban cambios profundos dentro de un orden socialista.

Consciente de los hechos que emergían con tanta fuerza y el riesgo que esto implicaba para los países capitalistas, tanto en los países centrales como en los de la periferia, a mediados de los setenta del siglo XX. la Comisión Trilateral elaboró un informe para tres de los gobiernos occidentales importantes (Japón, Estados Unidos y Francia), en el cual se hizo un diagnóstico de los problemas y causas que desde la perspectiva de los autores y los intereses que representaban, se constituían como centrales para el desempeño eficaz del gobierno y de la economía en las sociedades pos industriales con regímenes políticos democráticos. Este informe constituyó la visión neoconservadora más acabada en torno al funcionamiento de la democracia en las sociedades de mercado.

En síntesis, en esa década, frente a la crisis de las democracias, este informe impuso el concepto de gobernabilidad sobre el de legitimidad (que cuestionaba la estabilidad y moralidad del capitalismo), y cargó la culpa de los desórdenes a la participación ciudadana, o en otras palabras, a los excesos de democracia. En rigor, lo que pretende la Comisón Trilateral es que exista un culto a la uforma democrática", a saber, el culto a elecciones «libres", pluripartidismo, "libertad" de expresión, de asociación, etc., pero desprovista de contenido real, es decir, de la capacidad efectiva de decisión sobre los asuntos fundamentales de carácter político, económico y social. Se trata de impedir que las demandas sociales se impongan al Estado por medio de los mecanismos del sistema político.

El norteamericano Samuel Hantington, uno de los ideólogos de la Trilateral, propugnaba por las

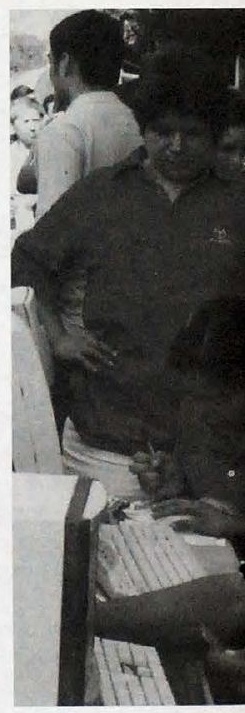


elecciones, apertura, libertad y juego limpio como esenciales para la democracia.

A partir de todo lo anterior y al calor de las nuevas categorías que han irrumpido en las ciencias sociales durante la década de los ochenta, las cuales están revestidas de realismo y pragmatismo, y hasta con rango de indiscutibles (de facto y en teoría), sobre todo a partir de la década de los 90 del siglo pasado donde cobran auge, intentamos rescatar el debate generado en las ciencias sociales con el ánimo de desmitificar las pretensiones de objetividad y actualidad con las que se nos representan dichas categorías. Las mismas que por sus criterios de análisis dejan por fuera en sus construcciones nudos gordianos, propios de las sociedades como la salvadoreña, esto es, las contradicciones inherentes al sistema y la eterna conflictividad de la sociedad, la cual recusa cualquier teoría en sus aspectos fundamentales cuando de transformar las sociedades se trata.

Toda la primera parte, rastrea la posición de la Comisión Trilateral y las nociones convocantes de la "nueva realidad", bajo los discursos alusivos a la transición a la democracia, la gobernabilidad democrática y la sacrosanta democracia liberal procidemental. Estos procesos que pretenden estudiar esas categorías aludidas, que sin embargo, aspiran a hablar en nombre de la realidad, se contrastan con una vocación diferente, rica en contenido por su pertenencia a una totalidad que desemboca en la denominada democracia gobernante, como proceso integral no reductible a procesos electorales cuestionados, ni mucho menos, porque sitúa a los seres humanos en su totalidad y realidad ontológica.

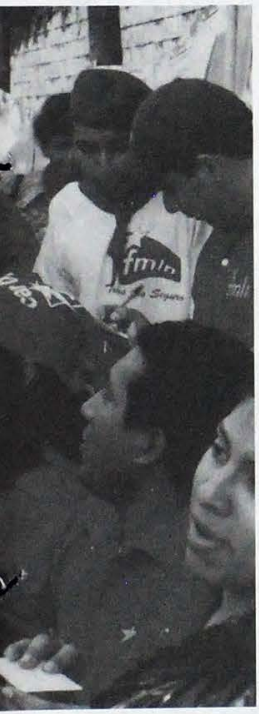

Mucho se han debatido las nociones de gobernabilidad en cuanto a literatura y reflexión de los procesos políticos, económicos y sociales de la región; a tal grado que el prestigiado sociólogo chileno Manuel Antonio Garretón la define como atributo del régimen y no del sistema global, desmarcándose del envoltorio ideológico reaccionario que marcó su origen en política y en las ciencias sociales.

En esa línea de pensamiento, Garretón entiende por gobernabilidad la capacidad que tiene un régimen determinado de cumplir las funciones típicas de todo régimen: la definición de las relaciones entre el individuo y el Estado, la forma de gobierno de la sociedad y la canalización institucional de demandas y conflictos sociales.

Por su parte, otro concepto alude al "equilibrio entre el nivel de las demandas societales y la capacidad del sistema político, para responderlas de manera legítima y eficaz. Esta definición, aun en su simplificadora brevedad, nos permite ubicar los problemas de gobernabilidad sobre el plano de la relación entre el sistema político y su entorno o ambiente. Es decir, la sociedad, evitando cargar a uno solo de los términos de la relación de gobierno con el peso por mantener adecuadas condiciones de gobernabilidad. En otras palabras, no es un Estado o gobierno lo que permiteperse- gobernar en sociedad, ni tampoco es la sociedad en sí misma gobernable o ingobernable, más bien, es la relación compleja entre ambos términos lo que permite hablar de las condiciones de gobernabilidad"'

Con ese telón de fondo, no resulta extraño que el Banco Mundial -MB-, organismo financiero internacional que otorga préstamos a los países necesitados de financiamiento, bajo condicionados sujetas a su visión del mundo, exija a los gobiernos niveles de gobernabilidad para desembolsar los empréstitos. Por ser parte fundamental del andamiaje financiero exterior, que por su misma naturaleza refrenda poder, sería ingenuidad de parte del BM, apartarse de una de las categoría consustanciales al oden del sistema capitalista como un todo, pues constituyen junto al Fondo Monetario Internacional el poder financiero mundial, por lo que, se convierten en guardianes del sistema y protectores de los intereses económicos que movilizan y desarrollan la denominada "globalización".

Por su parte, en relación a la democracia gobernable se discute el aporte del vienés Joseph Chumpeter, quien en su oportunidad dejó establecido que "...la democracia no significa ni puede

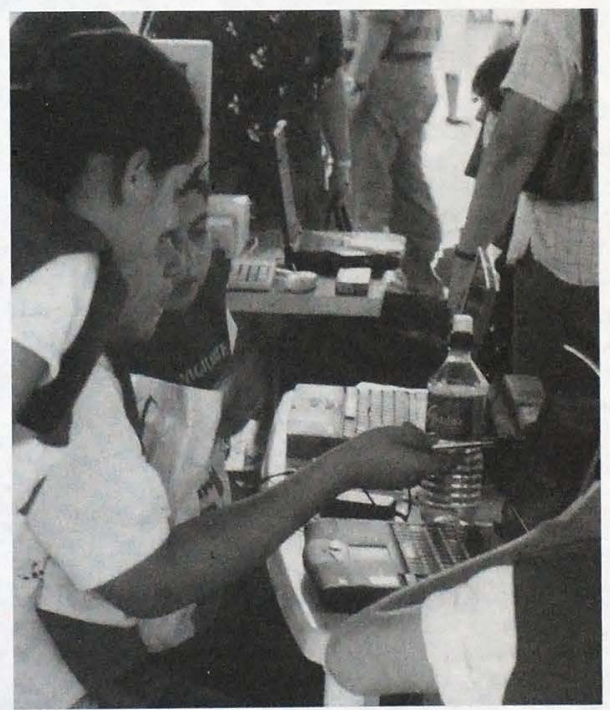


significar que el pueblo gobierna afectivamente, en ninguno de los sentidos evidentes de las expresiones 'pueblo' y 'gobernar'. La democracia significa tan sólo que el pueblo tiene la oportunidad de aceptar o rechazar los hombres que han de gobernarle" ${ }^{2}$. Este pensamiento político ha marcado el pensamiento y acción a cuantos gobiernos han sido elegidos por ese procedimiento desde la instauración de la democracia gobernable, como forma distinta al autoritarismo que ejercieron los militares en su paso por el poder político, sobre todo desde el decenio de los ochenta del siglo pasado en América Latina.

Tras la implementación de las políticas neoliberales que aplicaron los distintos gobiernos (centro izquierda y derecha o conservadores), la gobernabilidad que se recomienda y se impone, tiene por finalidad, el logro del control político y social de la población; y se fundamenta en un andamiaje institucional para garantizar la estabilidad y el orden, en el contexto de un modelo de administración de la sociedad, de una idea de la sociedad que polariza los campos sociales por la generación de niveles crecientes de inequidad y desigualdad social. Desde esta perpsectiva, esa gobernabilidad, en absoluto, es democrática; en ese sentido, la direccionalidad de la gobernabilidad sepultó la direccionalidad de la democracia.

Uno de los instrumentos de la democracia gobernable, por antonomasia, es la representación, expresada por medio de los partidos políticos, quienes no sólo representan diferencias de votos, sino que: que representan el interés capitalista que tiene detrás toda la estructura de poder (empresarios, fuerzas armadas y policiales, burocracias estatales y partidarias, medios de comunicación, cúpulas de la Iglesia y narcotráfico), mientras que la izquierda debe construir permanentemente su fuerza social, y ello no se hace desmovilizándola para negociar. Sin embargo, ha calado tan hondo en varios partidos de izquierda que los conflictos sociales son dañinos para la democracia, y de este modo se sitúan en las lógicas conservadoras de la gobernabilidad.

Generalmente, quienes defienden la posición anterior son las adscripciones ideológicas asociadas a la socialdemocracia o llamadas a sí mismo como izquierda democrática. De ahí que la democracia liberal fundamentada en la representación gire alrededor de las elecciones, otorgando un papel pasivo a los electores y un papel dinámico a los representantes, en quienes recae principalmente tomar las decisiones en nombre del conjunto de ciudadanos.

Al guardar distancia con la democracia liberal y sus fundamentos indicados, así como de la noción de gobernabilidad (democrática), a la que aluden muchas instancias de la sociedad política y la sociedad civil, se está acotando la línea divisoria en la que argumentamos su antítesis, es decir, la democracia gobernante. Por su puesto que son rescatables en nuestra visión las elecciones, pero sometidas a otra lógica que fuercen a una relación

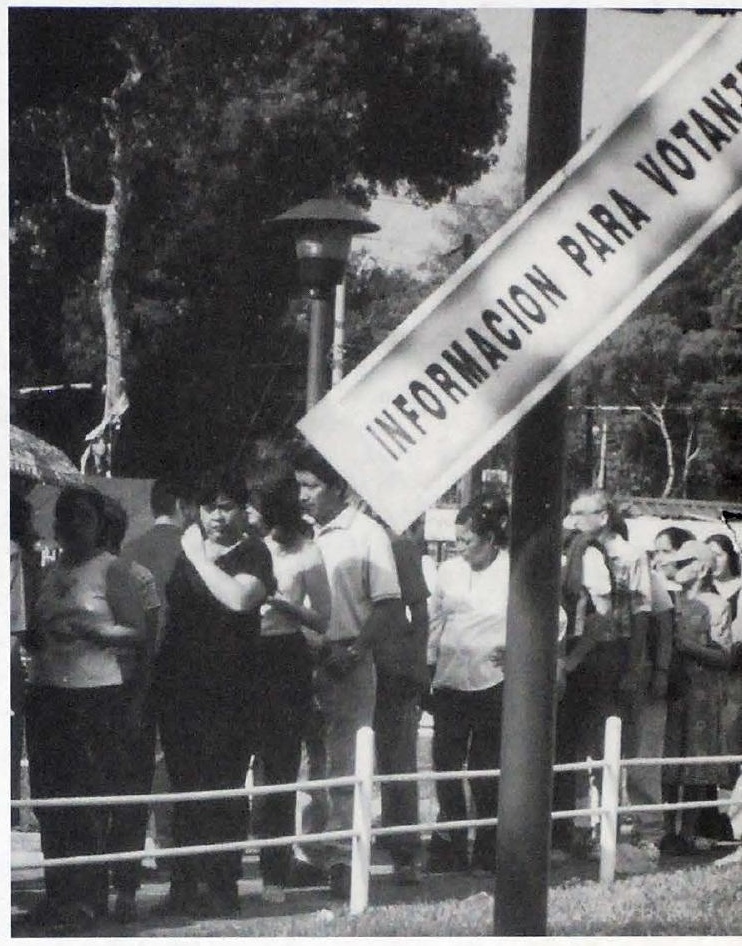

permanente entre representantes y representados, pasando por la revocatoria.

Por supuesto que el sentido de crítica a la que sometemos las nociones anteriores no tendría ningún asidero y justificación si no proponemos una salida normativa al problema en cuestión. De ahí que se propugne en esta investigación, por una alternativa que represente un proyecto democrático de alcance distinto al que solemos conocer actualmente, como forma de gobierno y/o sistema político, a fin de poner en el centro de la discusión una democracia gobernante que nazca de otros criterios en las formas de relación entre gobernantes y gobernados, teniendo como eje neurálgico, una activa y fuerte participación de los distintos sectores de la sociedad en las decisiones que se adopten.

La democracia como forma de vida y participativa en la resolución de los problemas de la sociedad, es la antítesis a la democracia liberal vigente en El Salvador, que por ser ésta simplemente procedimental, carece de mayor compromiso para responder a las necesidades de la inmensa mayoría de salvadoreños. 
